\title{
HOMOGENEOUS IGNITION IN HIGH-PRESSURE COMBUSTION OF METHANE/AIR OVER PLATINUM: COMPARISON OF MEASUREMENTS AND DETAILED NUMERICAL PREDICTIONS
}

\author{
MICHAEL REINKE, JOHN MANTZARAS, ROLF SCHAEREN, ROLF BOMBACH, \\ WOLFGANG KREUTNER AND ANDREAS INAUEN \\ Paul Scherrer Institute \\ Combustion Research \\ CH-5232 Villigen-PSI, Switzerland
}

\begin{abstract}
The gas-phase ignition of fuel-lean methane/air premixtures over Pt was investigated experimentally and numerically in laminar channel-flow configurations at pressures of up to 10 bar. Experiments were performed in an optically accessible catalytic channel reactor established by two Pt-coated ceramic plates, $300 \mathrm{~mm}$ long (streamwise direction) and placed $7 \mathrm{~mm}$ apart (transverse direction). Planar laser-induced fluorescence (PLIF) of the $\mathrm{OH}$ radical along the streamwise plane of symmetry was used to monitor the onset of homogeneous (gas-phase) ignition, and thermocouples embedded beneath the catalyst provided the surface temperature distribution. Computations were carried out with a two-dimensional elliptic numerical code, which included the elementary heterogeneous (catalytic) reaction scheme for methane on Pt from Deutschmann and two different elementary homogeneous reaction schemes, Warnatz and GRI3.0. Following homogeneous ignition, very stable V-shaped flames were established in the reactor. At pressures of up to $6 \mathrm{bar}$, the measured and predicted (Deutschmann/Warnatz schemes) flame sweep angles and $\mathrm{OH}$ levels were in good agreement with each other, while the homogeneous ignition distances were predicted within $10 \%$. However, at pressures greater than or equal to 8 bar, a marked overprediction of the homogeneous ignition distances was evident (>25\%). The Deutschmann/GRI-3.0 schemes yielded much shorter $(\sim 55 \%-65 \%)$ homogeneous ignition distances at all pressures. Sensitivity analysis indicated that the latter discrepancies were ascribed to the homogeneous reaction pathway. GRI-3.0 yielded a much faster radical pool buildup than the scheme of Warnatz, clearly showing its inapplicability under catalytically stabilized combustion (CST) relevant conditions. The heterogeneous reactivity was enhanced with increasing pressure. Although the increase in pressure inhibited the adsorption of methane due to the resulting higher oxygen surface coverage, this effect was overtaken by the corresponding increase of the methane gas-phase concentration.
\end{abstract}

\section{Introduction}

The advancement of catalytically stabilized combustion (CST) to practical devices requires the development of catalysts with enhanced activity and thermal stability, the knowledge of heterogeneous (catalytic) kinetics and their coupling with low-temperature homogeneous (gas-phase) kinetics, and the availability of improved numerical models. In particular, multidimensional CFD codes $[1,2]$ supplemented with validated hetero/homogeneous chemical reaction schemes can aid considerably the design of CST reactors. Methane is the main fuel component of CST-based power systems and the understanding of its heterogeneous kinetics on precious metals has progressed significantly, for both the total $[3]$ and partial $[1,4]$ oxidation routes. Complementing the previous heterogeneous kinetic studies, combined hetero/homogeneous chemical reaction schemes for $\mathrm{CH}_{4} /$ air CST over Pt were validated recently [5] in their capacity to reproduce measured homogeneous ignition characteristics at atmospheric pressure. Homogeneous ignition is detrimental to the catalyst integrity and, therefore, the delineation of safe operating conditions that ensure no gas-phase combustion inside the catalytic reactor is of prime importance. To this direction, homogeneous ignition criteria for channel-flow CST were developed recently [6], elucidating the dependence of the homogeneous ignition distance on the relevant flow, transport, chemical, and geometrical channel-flow parameters; they were further adapted to atmospheric-pressure $\mathrm{CH}_{4} /$ air CST over Pt in Mantzaras et al. [7], using the hetero/homogeneous schemes that were validated in Dogwiler et al. [5].

High-pressure operation, typical of many practical systems, exacerbates the potential of homogeneous ignition due to the enhanced reactivity of hydrocarbons with increasing pressure [8]. Therefore, in parallel with surface science studies of heterogeneous processes under realistic pressures [9], the understanding of high-pressure hetero/homogeneous 


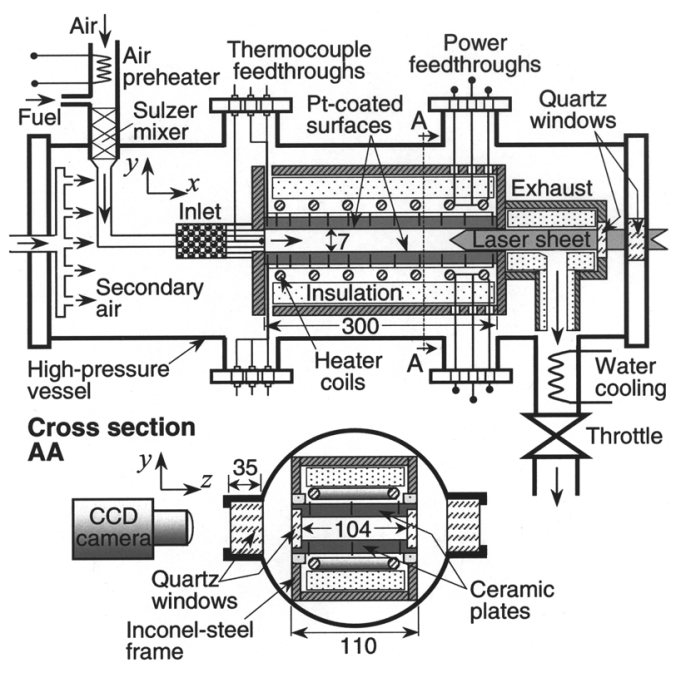

FIG. 1. Schematic of the high-pressure catalytic combustion test rig and the OH PLIF arrangement. All distances are in millimeters. The reactor volume is defined by the $300 \times 104 \times 7 \mathrm{~mm}^{3}$ enclosure.

combustion is cardinal for CST. The present study undertakes an experimental and numerical investigation of high-pressure $\mathrm{CH}_{4}$ /air $\mathrm{CST}$ over $\mathrm{Pt}$, with the main objective to validate the CST applicability of various hetero/homogeneous reaction schemes. A particular objective was to investigate the effect of pressure on the underlying hetero/homogeneous processes. Experiments were performed in an optically accessible, laminar channel-flow catalytic reactor with Pt-coated walls, at pressures of up to 10 bar. Planar laser-induced fluorescence (PLIF) of the $\mathrm{OH}$ radical was used to monitor the onset of homogeneous ignition and thermocouples embedded beneath the catalyst yielded the surface temperature distribution. The numerical predictions included a two-dimensional elliptic fluid mechanical model, which included the heterogeneous scheme for the total oxidation of $\mathrm{CH}_{4}$ over Pt by Deutschmann et al. [3] and the homogeneous schemes of Warnatz and Maas [10] and GRI-3.0 [11].

\section{Experimental}

\section{High-Pressure Burner}

The test-rig (see Fig. 1) consisted of an optically accessible catalytic channel reactor, which formed a liner inside a 1.8-m-long and 0.28-m-in-diameter high-pressure cylindrical vessel. The reactor itself comprised two horizontal $\mathrm{Si}[\mathrm{SiC}]$ ceramic plates $300 \mathrm{~mm}$ long and placed $7 \mathrm{~mm}$ apart, supported on an inconel-steel frame. Two 3-mm-thick quartz windows (spring pressed against the ceramic plates) formed the other two channel surfaces. Plasma vapor deposition was used to coat the inner $\mathrm{Si}[\mathrm{SiC}]$ surfaces with a $1.5-\mu$ m-thick non-porous $\mathrm{Al}_{2} \mathrm{O}_{3}$ layer followed by a $2.2-\mu \mathrm{m}$-thick Pt layer. The surface temperature along the streamwise plane of symmetry was measured by S-type thermocouples (12 for each plate) embedded $0.9 \mathrm{~mm}$ beneath the catalyst through holes eroded from the outer, inert $\mathrm{Si}[\mathrm{SiC}]$ surfaces. The catalyst plate temperatures were controlled independently by two resistive heaters positioned above the outer ceramic surfaces. The air was preheated, mixed with $\mathrm{CH}_{4}$ in two static mixers, passed through a 40-mm-long section filled with ceramic spheres $2 \mathrm{~mm}$ in diameter, and then through a 50-mm-long inert honeycomb placed just upstream of the channel entrance to attain a uniform inlet velocity profile. A thermocouple positioned at the downstream end of the honeycomb monitored the reactor inlet temperature. The air and methane flow rates were regulated with two BROOKS mass flow controllers. A small amount of secondary air (supplied by a distribution ring) flushed the volume between the liner and the vessel from unwanted combustion products. To facilitate optical accessibility, the high-pressure vessel had two 350-mm-long and 35-mm-thick quartz side windows at the same axial locations as the windows of the reactor. Two additional quartz windows located at the reactor's exhaust section and the rear flange of the high-pressure vessel, respectively, provided a streamwise optical access through which the PLIF laser sheet was introduced into the reactor (Fig. 1). All thermocouples and power inputs were driven to the reactor via high-pressure feedthroughs.

\section{Laser Diagnostics}

A frequency-doubled Nd:YAG pulsed laser (Quantel YG781C20) pumped a tunable dye laser (Quantel TDL50). Its frequency-doubled radiation $(285 \mathrm{~nm}$ ) was transformed into a laser sheet by a cylindrical lens telescope and a 1-mm slit mask. The laser sheet propagated counterflow, along the $x-y$ symmetry plane from the exhaust side (Fig. 1). The pulse energy was low enough $(0.5 \mathrm{~mJ})$ to avoid saturation of the $A(v=1) \rightarrow X\left(v^{\prime}=0\right)$ transition. The fluorescence of both $\mathrm{OH}(1-1)$ and (0-0) transitions at 308 and $314 \mathrm{~nm}$, respectively, was collected at $90^{\circ}$ through one of the vessel's side windows with an intensified CCD camera (LaVision FlameStar 2F, $576 \times 384$ pixels) equipped with a $105-\mathrm{mm}$ focal length $\mathrm{f} / 4.5$ lens (Nikon UV-Nikkor) and a band-pass filter centered at $310 \mathrm{~nm}$. A $67 \times 7 \mathrm{~mm}^{2}$ section of the combustor was imaged on a $576 \times 60$ pixel area: the camera was traversed axially to map the entire 300-mm channel extent. As the flow conditions were laminar, 100 images were averaged to increase the signal-to-noise ratio. The OH PLIF was calibrated with absorption measurements performed with the 
vertical laser sheet crossing laterally $(z$ direction) the reactor through the side windows. This arrangement provided the only possible through-access needed for the calibration and was the same as in earlier atmospheric-pressure $\mathrm{CH}_{4} /$ air CST studies [5]. Given the absorption path length and the Einstein factor of the Q1(7) OH line (including pressure broadening), the concentration at the location of the absorption measurement could be deduced at each particular pressure. The concentrations in the other parts of the flame were calculated by scaling the fluorescence signal to that of the absorption location. This was a very good approximation since the quenching was nearly constant everywhere given the very lean premixed conditions and the small temperature variations across the flame. In that, modeling of the quenching was not necessary.

\section{Numerical}

A two-dimensional elliptic CFD code based on a finite-volume approach was used (see Refs. $[2,12]$ ). Gaseous and surface reaction rates were evaluated with CHEMKIN [13] and Surface-CHEMKIN [14]. Gaseous and surface thermodynamic data were taken from CHEMKIN [15] and Warnatz et al. [16], respectively. Mixture-average diffusion, including thermal diffusion for the light species [17], was used in the species transport. For surface chemistry, the $\mathrm{CH}_{4} / \mathrm{O}_{2}$ scheme on Pt by Deutschmann et al. [3] was employed (11 surface species, 9 gaseous species, and 24 reactions). The surface site density was $2.7 \times$ $10^{-9} \mathrm{~mol} / \mathrm{cm}^{2}$, simulating polycrystalline platinum $[2,3]$; the $2.2-\mu \mathrm{m}$-thick platinum layer on top of a non-porous $\mathrm{Al}_{2} \mathrm{O}_{3}$ layer closely resembled such a surface. For the very lean mixtures of this study, two $\mathrm{C}_{1} / \mathrm{H} / \mathrm{O}$ gaseous mechanisms were used: Warnatz and Maas [10], further denoted as Warnatz (106 reactions and 19 species including $\mathrm{N}_{2}$ ) and GRI-3.0 [11] (242 reactions and 22 species). The pressure dependence in Warnatz's scheme was modeled according to Warnatz et al. [18].

Computations were performed over half the channel domain $\left(300 \times 3.5 \mathrm{~mm}^{2}\right)$. An orthogonal staggered grid of $420 \times 80$ grid points (in $x$ and $y$, respectively) was sufficient to produce a grid-independent solution. The inlet boundary conditions were uniform profiles for the temperature, the axial velocity, and the species mass fractions. Fitted curves through the individual thermocouple measurements provided the wall-temperature profiles. The profiles of both plates differed, at any axial location, by a maximum of $\pm 8 \mathrm{~K}$. The average temperature profile between both plates was used as the energy wall boundary condition; computations have shown that the aforementioned local random platetemperature differences resulted in ignition distance differences of the order of $\sim 3 \%$, a factor well within the overall experimental uncertainty. No-slip conditions were used for both velocity components at the wall $(y=0)$ and zero-Neumann conditions at the plane of symmetry $(y=3.5 \mathrm{~mm})$ and the channel outlet $(x=300 \mathrm{~mm})$ for all scalars.

\section{Results and Discussion}

Comparisons between measured and predicted distributions of the $\mathrm{OH}$ radical are illustrated in Fig. 2; the predictions refer to the Deutschmann/Warnatz schemes. All flow conditions were laminar, with incoming Reynolds numbers $\left(R e_{\mathrm{IN}}\right)$ ranging from 632 to 1268 (see legend of Fig. 2). Once established, the stability and reproducibility of all V-flames with regard to their shapes and anchoring positions were excellent over extended measuring times; hence, the PLIF images of Fig. 2 were constructed by joining successive 67-mm-long camera records. The homogeneous ignition distance $\left(x_{\mathrm{ig}}\right)$ was defined by the intersection with the wall of lines (at an angle equal to the average flame sweep angle) fitted through the flame tails of Fig. 2. With increasing pressure, the inlet velocity was reduced (see legend of Fig. 2) to maintain a laminar flow. As the homogeneous ignition distance in channel-flow CST scaled with $R e_{\text {IN }}$ (see discussion in Ref. [7]), an increase in $R e_{\text {IN }}$ through an increase in pressure would have inhibited homogeneous ignition if the gaseous pathway remained unaffected by pressure. However, notwithstanding the twofold increase in $R e_{\text {IN }}$ when the pressure was increased from 3 to $10 \mathrm{bar}$, all measured flames of Fig. 2 ignited at about the same axial locations, clearly indicating an increase of the gaseous reactivity with increasing pressure. As seen from Fig. 2, the agreement between measured and predicted homogeneous ignition distances was, irrespective of $\varphi$, particularly good (within $\sim 6 \%$ ) at pressures of up to 4 bar with a somewhat increased deviation $(\sim 10 \%)$ at $6 \mathrm{bar}$; the good agreement was also extended to the sweep angles of the $\mathrm{V}$ flames and in the absolute $\mathrm{OH}$ concentrations. At even higher pressures, the deviations became larger $(>25 \%$, cases 6 and 7 ). In case 5 , the predictions did not capture the formation of a V-shaped flame; conditions similar to case 5 were common at pressures $\geq 8$ bar. Fig. 3 illustrates the computed average (over the transverse direction) mole fractions of $\mathrm{CH}_{4}, \mathrm{CO}$, $\mathrm{OH}$, the fractional $\mathrm{CH}_{4}$ conversions, and the measured wall temperature profiles. The $\mathrm{CH}_{4}$ consumption was accompanied by the buildup of $\mathrm{CO}$; in cases 1 and 4, both $\mathrm{CH}_{4}$ and $\mathrm{CO}$ were consumed shortly after homogeneous ignition, with practically no $\mathrm{CH}_{4}$ or unburned CO escaping at the channel exit. At the ignition point, both reaction pathways had already converted $82 \%$ and $76 \%$ of $\mathrm{CH}_{4}$ in cases 1 and 4 (Fig. 3), respectively; the corresponding values were 


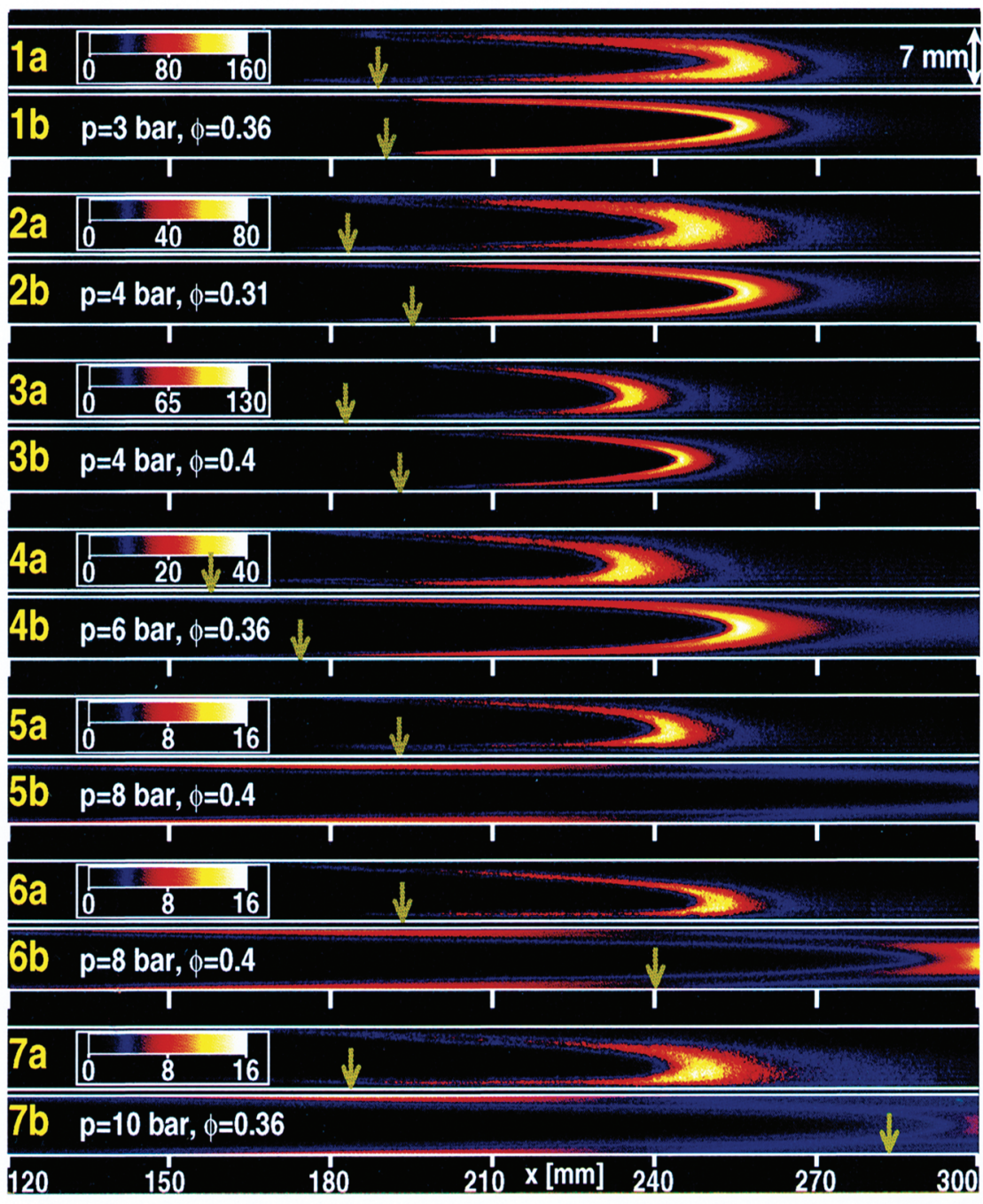

FIG. 2. PLIF-measured (1a-7a) and -predicted ( $1 \mathrm{~b}-7 \mathrm{~b})$ OH concentrations (ppmv). The predictions refer to the Deutschmann/Warnatz chemical reaction schemes. The rear section of the catalytic channel is shown $(120 \leq x \leq 300$ $\mathrm{mm})$. The green arrows illustrate the onset of homogeneous ignition. The experimental conditions are: (1) $p=3 \mathrm{bar}$, $\varphi=0.36, U_{\mathrm{IN}}=0.75 \mathrm{~m} / \mathrm{s}, T_{\mathrm{IN}}=560 \mathrm{~K}, R e_{\mathrm{IN}}=640 ;(2) p=4 \operatorname{bar}, \varphi=0.31, U_{\mathrm{IN}}=0.56 \mathrm{~m} / \mathrm{s}, T_{\mathrm{IN}}=562 \mathrm{~K}, R e_{\mathrm{IN}}=$ 632 ; (3) $p=4$ bar, $\varphi=0.4, U_{\mathrm{IN}}=0.55 \mathrm{~m} / \mathrm{s}, T_{\mathrm{IN}}=546 \mathrm{~K}, \operatorname{Re} e_{\mathrm{IN}}=645$; (4) $p=6$ bar, $\varphi=0.36, U_{\mathrm{IN}}=0.47 \mathrm{~m} / \mathrm{s}$, $T_{\mathrm{IN}}=563 \mathrm{~K}, R e_{\mathrm{IN}}=790 ;(5) p=8 \mathrm{bar}, \varphi=0.4, U_{\mathrm{IN}}=0.57 \mathrm{~m} / \mathrm{s}, T_{\mathrm{IN}}=567 \mathrm{~K}, R e_{\mathrm{IN}}=1263$; $(6) p=8 \mathrm{bar}, \varphi=$ $0.4, U_{\mathrm{IN}}=0.52 \mathrm{~m} / \mathrm{s}, T_{\mathrm{IN}}=566 \mathrm{~K}, R e_{\mathrm{IN}}=1149 ;(7) p=10 \mathrm{bar}, \varphi=0.36, U_{\mathrm{IN}}=0.47 \mathrm{~m} / \mathrm{s}, T_{\mathrm{IN}}=571 \mathrm{~K}, R e_{\mathrm{IN}}=$ 1268. The inlet Reynolds numbers were based on the channel hydraulic diameter $(=13.1 \mathrm{~mm})$. The levels of $\mathrm{OH}$ for each pair of images (measured and computed) are indicated by the color-coded bars.

$81 \%$ and $88 \%$ for cases 2 and 3. Such large preignition $\mathrm{CH}_{4}$ conversions were much desired to exemplify the degree of hetero/homogeneous coupling.

The underlying hetero/homogeneous processes are further elucidated in Fig. 4 (case 4), which illustrates the computed heterogeneous and homogeneous production rates of four species. Throughout the entire channel length, $\mathrm{CH}_{4}$ was consumed by both reaction pathways, whereas throughout the preignition zone $\mathrm{CO}$ and $\mathrm{H}_{2}$ were produced by the gaseous and consumed by the catalytic pathway. In the early preignition zone, $\mathrm{OH}$ was produced by the surface and consumed by the gaseous pathway; however, at the latest preignition stages $(x>145 \mathrm{~mm})$ the heterogeneous pathway became a sink of $\mathrm{OH}$ 


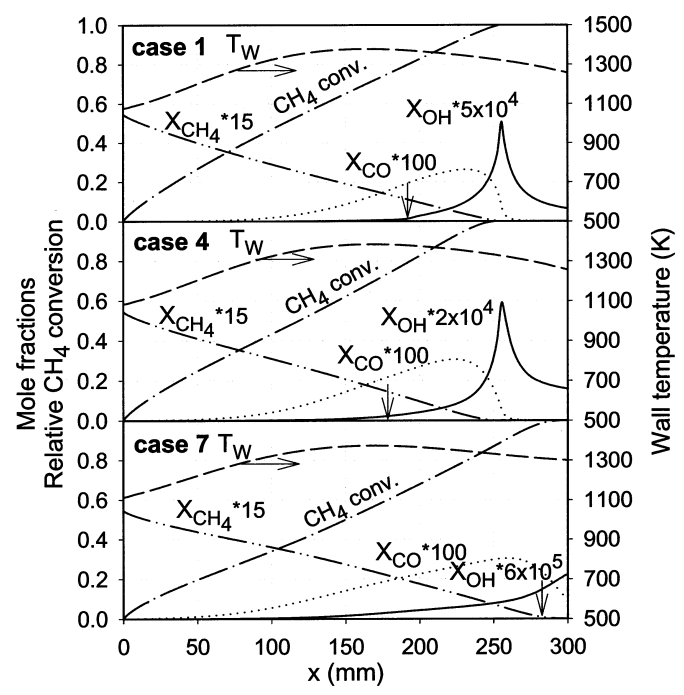

FIG. 3. Profiles of the computed average (over the channel transverse direction) species mole fractions $\left(\mathrm{CH}_{4}\right.$, dashed-double dotted; $\mathrm{CO}$, dotted; and $\mathrm{OH}$, solid), fractional $\mathrm{CH}_{4}$ conversion summed over the heterogeneous and homogeneous pathways (dashed-dotted lines), and measured wall temperature averaged over top and bottom catalyst plates (dashed lines), cases 1 ( 3 bar), 4 (6 bar), and 7 (10 bar). All computations refer to the hetero/homogeneous schemes of Deutschmann/Warnatz. The predicted homogeneous ignition distances are shown by the vertical arrows.

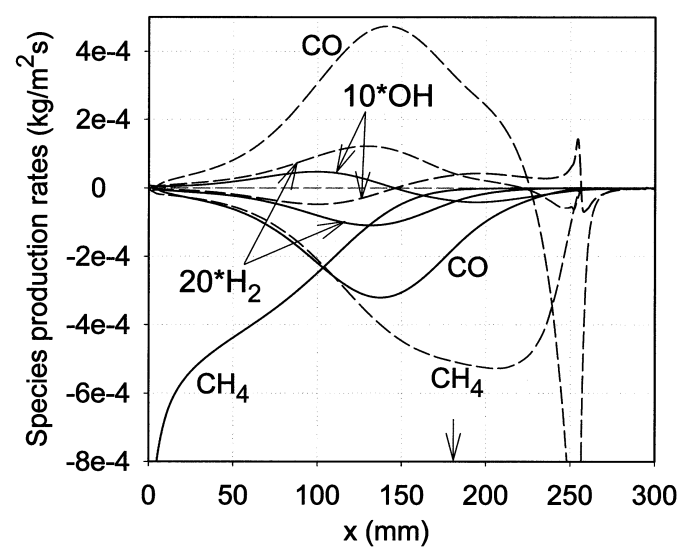

FIG. 4. Streamwise profiles of predicted (Deutschmann/ Warnatz schemes) species production rates for case 4 (6 bar). The solid lines denote the heterogeneous pathway and the dashed lines the homogeneous pathway. The contribution of the homogeneous pathway has been integrated over the transverse direction. The vertical arrow indicates the computed location of homogeneous ignition. In the preignition zone, $\mathrm{CO}$ and $\mathrm{H}_{2}$ were produced by the gaseous and consumed by the surface pathway, their net rates of production being positive.

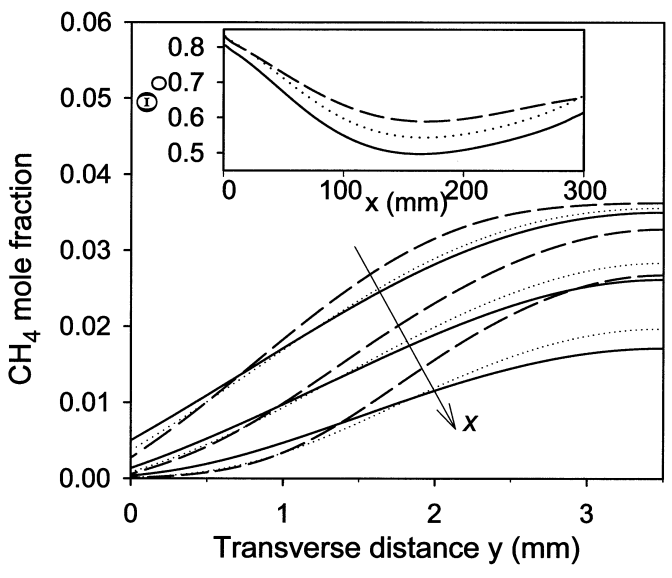

FIG. 5. Transverse profiles of the $\mathrm{CH}_{4}$ mole fraction and streamwise profiles of oxygen coverage (Inset). Case 1 ( 3 bar), solid lines; case 4 (6 bar), dotted lines; and case 7 (10 bar), dashed lines. The case notation is the same as in Fig. 2. The catalytic wall is located at $y=0$. The transverse $\mathrm{CH}_{4}$ profiles refer to three selected axial locations: $x=38$, 96 , and $154 \mathrm{~mm}$. The arrow points to the direction of increasing axial distance. The Inset provides the streamwise profiles of the oxygen surface coverage $\left(\Theta_{\mathrm{O}}\right)$ for cases 1,4 , and 7 ; the line notation is the same as in the main figure.

radicals that resulted in an overall mild homogeneous ignition inhibition. This was confirmed by removing both $\mathrm{OH}$ adsorption/desorption reactions and computing anew; the $x_{\mathrm{ig}}$ was reduced by about $10 \%$. In case 7 (10 bar) of Fig. 2, the numerical predictions indicated a weak ignition occurring $\sim 50 \%$ farther downstream of the measured location. At the ignition location, $98 \%$ of the methane was already consumed (Fig. 3); moreover, the in-channel flame residence time was not sufficient, so that considerable amounts of unburned $\mathrm{CO}$ were computed at the reactor exit (1050 ppmv). This was even more pronounced in the predictions of case 5 , which did not capture the formation of the V-shaped flame; large amounts of $\mathrm{CH}_{4}$ and $\mathrm{CO}$ exited the reactor (e.g., $8 \%$ unburned $\mathrm{CH}_{4}$ and 3650 ppmv $\mathrm{CO}$ ). The foregoing have exemplified the importance of the hybrid CST combustion approach [19], since the heterogeneous pathway itself, without a subsequent postcatalyst flame, cannot provide complete $\mathrm{CO}$ burnout. The important conclusion reached from the comparisons of Fig. 2 is the validation of the Deutschmann/Warnatz schemes at pressures of up to $6 \mathrm{bar}$, a range of particular interest in microturbine applications.

The purely surface processes are investigated in Fig. 5 with the transverse $\mathrm{CH}_{4}$ profiles (at three selected preignition axial locations) and the streamwise coverage of oxygen $\left(\Theta_{\mathrm{O}}\right)$, the dominant surface species. With increasing pressure (and hence $R e_{\mathrm{IN}}$ ), the 


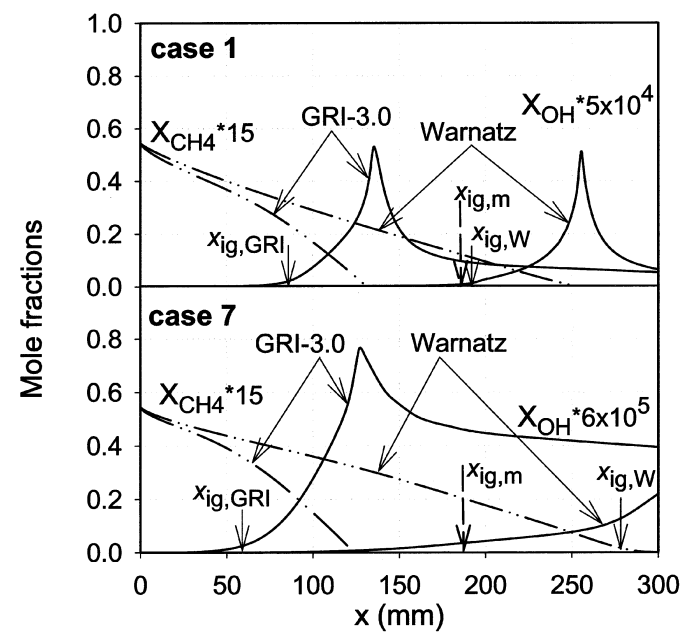

FIG. 6. Streamwise profiles of computed average (over the channel transverse direction) $\mathrm{CH}_{4}$ and $\mathrm{OH}$ mole fractions for cases 1 ( 3 bar) and 7 (10 bar). Computations with two different gaseous schemes (and the heterogeneous scheme of Deutschmann), Warnatz and GRI-3.0. Dasheddouble dotted lines, $\mathrm{CH}_{4}$; solid lines, $\mathrm{OH}$. The vertical solid arrows indicate the predicted homogeneous ignition locations with the schemes of Warnatz $\left(x_{\mathrm{ig}, \mathrm{W}}\right)$, GRI-3.0 $\left(x_{\mathrm{ig}, \mathrm{GRI}}\right)$ and the vertical dashed arrows the measured ones $\left(x_{\mathrm{ig}, \mathrm{m}}\right)$.

fractional $\mathrm{CH}_{4}$ catalytic conversion decreased as manifested by the corresponding higher $\mathrm{CH}_{4}$ levels near the channel center. Although the transverse fluid mechanical transport was augmented at higher pressures due to the increase in $R e_{\text {IN }}$, the low $\mathrm{CH}_{4}$ wall levels of Fig. 5 indicated that the surface reactions were still able to cope with this increase; the methane conversion was practically mass-transportlimited in all cases and, moreover, the wall $\mathrm{CH}_{4}$ levels were somewhat lower in the higher-pressure cases. This was due to the increased heterogeneous reactivity at higher pressures, for the reasons explained next. The inset of Fig. 5 indicated higher oxygen coverage at higher pressures due to the corresponding increase of the oxygen partial pressure. The $\Theta_{\mathrm{O}}$ profiles had a minimum at the location of maximum wall temperature (see Fig. 3) due to the negative temperature dependence of the $\mathrm{O}_{2}$-sticking coefficient [3]; the minimum $\Theta_{\mathrm{O}}$ levels in all profiles of Fig. 5, however, reflected the $\mathrm{O}_{2}$ partial pressure effect, as the maximum wall temperatures of the three cases differed by only $9 \mathrm{~K}$. The initiation step of the surface mechanism was $\mathrm{CH}_{4}$ adsorption, which had an overall order of 2.3 with respect to the free site coverage [3], the free coverage being practically $\Theta_{\mathrm{Pt}} \approx 1-\Theta_{\mathrm{O}}$. The resulting $\mathrm{CH}_{4}$ adsorption rate was $R_{\text {ads }} \propto \gamma_{\mathrm{CH} 4} \Theta_{\mathrm{Pt}}^{2.3}\left[\mathrm{CH}_{4}\right]$, with $\gamma_{\mathrm{CH} 4}$ the methane-sticking coefficient and $\left[\mathrm{CH}_{4}\right]$ the wall concentration of methane. Therefore, the increase in
$\Theta_{\mathrm{O}}$ with increasing pressure inhibited the heterogeneous reactivity due to the reduced availability of free sites. The factor $\Theta_{\mathrm{Pt}}^{2.3}$ decreased by a maximum of $60 \%$ when the pressure increased from 3 to 10 bar; however, the nearly 3 -fold increase in methane near-wall concentration $\left(\left[\mathrm{CH}_{4}\right] \propto p\right)$ overtook this reduction, resulting in an overall increased highpressure catalytic reactivity.

Homogeneous ignition predictions with the Deutschmann/GRI-3.0 schemes are illustrated in Fig. 6. GRI-3.0 underpredicted homogeneous ignition substantially (by $\sim 55 \%-65 \%$ ) over the entire pressure range, notwithstanding its more detailed kinetic description. Computations with the $\mathrm{C}_{2} / \mathrm{H} / \mathrm{O}$ GRI-3.0 mechanism yielded the same ignition predictions with those of the $\mathrm{C}_{1} / \mathrm{H} / \mathrm{O}$ mechanism. Comparisons of atmospheric-pressure predictions with the Deutschmann/Warnatz schemes (validated in Ref. [5]) and Deutschmann/GRI-3.0 schemes have also revealed similar discrepancies. Therefore, GRI-3.0 has strong deficiencies in CST at pressures of 1-10 bar. It is emphasized that the heterogeneous pathway cannot be held responsible for the performance of GRI-3.0, for the following reasons. If a heterogeneous scheme faster than Deutschmann's scheme was used, it would not influence significantly the location of homogeneous ignition, since the catalytic conversion is already close to its mass-transport limit (see Fig. 5), and hence, the near-wall $\mathrm{CH}_{4}$ levels (which are crucial for homogeneous ignition) are not dictated by kinetics. On the other hand, a slower heterogeneous scheme would drive the catalytic conversion toward the kinetically controlled regime leading to a near-wall $\mathrm{CH}_{4}$ excess that would, in turn, result in an even earlier homogeneous ignition. This is also shown in the surface sensitivity analysis (SA) of Fig. 7a; the pre-exponential constant of every reaction in Deutschmann's scheme was multiplied (divided) by a given factor $K$ and the computations were repeated. The most significant surface reactions for homogeneous ignition were the same, irrespective of pressure, gaseous mechanism (Warnatz or GRI-3.0), factor $K(K=10$ and 20 were used) and the particular test case. As seen, the surface pathway had a moderate influence on homogeneous ignition. The most sensitive reaction was $\mathrm{CH}_{4}$ adsorption; the highly skewed bars of this reaction reflected the transport limitations discussed above. In addition, the effect of radical $(\mathrm{OH}) \mathrm{ad}-$ sorption/desorption reactions on homogeneous ignition was particularly weak. The overall weak coupling of the heterogeneous and homogeneous pathways at conditions close to mass-transport-limited operation allowed for independent validation of the gas-phase mechanisms, as also shown in our previous atmospheric-pressure $\mathrm{H}_{2}$ /air CST studies [20].

A gas-phase SA was performed by multiplying the pre-exponential constants of each gaseous reaction by a factor $K$ (factors of $1.2,1.5$, and 2 produced the 

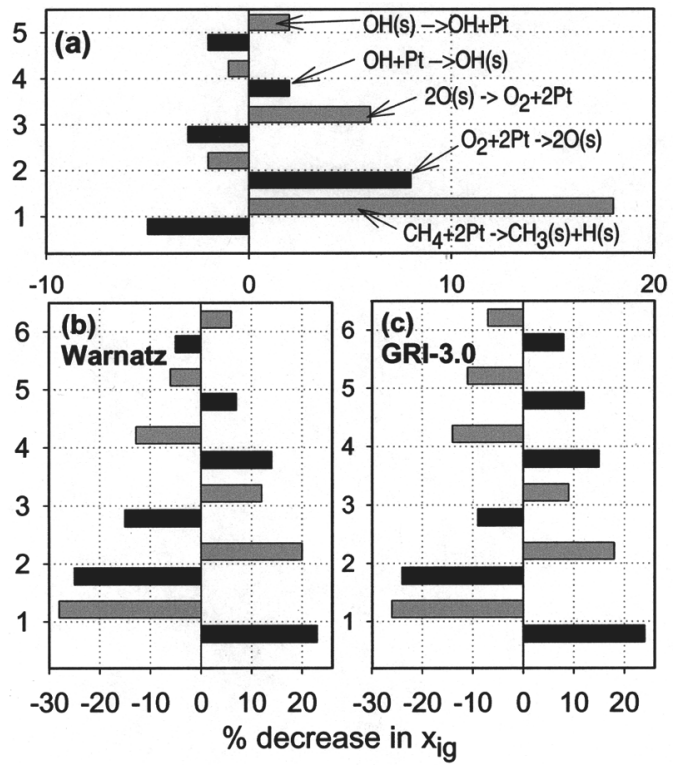

FIG. 7. Sensitivity analysis of surface and gaseous pathways on homogeneous ignition. The percentage decrease in the homogeneous ignition distance is shown for the most significant reactions; a multiplication (black bars) or division (gray bars) factor $K$ of the pre-exponential constant was used. The sensitivity analysis is qualitatively the same for pressures up to 10 bar (the results of Fig. 7 refer to 6 bar). (a) Surface sensitivity analysis, $K=10$. The five most significant reactions are given: reaction, 1 , methane adsorption; reaction 2 , oxygen adsorption; reaction 3 , oxygen desorption; reaction 4, $\mathrm{OH}$ adsorption; reaction $5, \mathrm{OH}$ desorption. The suffix (s) denotes a surface species. (b) Sensitivity analysis on the gaseous scheme of Warnatz $(K=$ 2 ). The six most significant reactions are given. The reaction numbering is: reaction $1, \mathrm{O}_{2}+\mathrm{H}=\mathrm{OH}+\mathrm{O}$; reaction $2, \mathrm{H}+\mathrm{O}_{2}+\mathrm{M}=\mathrm{HO}_{2}+\mathrm{M}$; reaction $3, \mathrm{HO}_{2}+$ $\mathrm{OH}=\mathrm{H}_{2} \mathrm{O}+\mathrm{O}_{2}$; reaction $4, \mathrm{CH}_{3}+\mathrm{O}_{2}=\mathrm{CH}_{2} \mathrm{O}+\mathrm{O}$ $+\mathrm{H}$; reaction $5, \mathrm{CH}_{4}+\mathrm{OH}=\mathrm{CH}_{3}+\mathrm{H}_{2} \mathrm{O}$; reaction 6 , $\mathrm{CH}_{3}+\mathrm{OH}=\mathrm{CH}_{2} \mathrm{O}+\mathrm{H}_{2}$. Sensitivity analysis on gaseous scheme of GRI-3.0 $(K=2)$. The six most significant reactions are given. The reaction numbering is: reaction 1 , $\mathrm{O}_{2}+\mathrm{H}=\mathrm{OH}+\mathrm{O}$; reaction $2, \mathrm{H}+\mathrm{O}_{2}+\mathrm{M}=\mathrm{HO}_{2}$ $+\mathrm{M}$; reaction $3, \mathrm{HO}_{2}+\mathrm{OH}=\mathrm{H}_{2} \mathrm{O}+\mathrm{O}_{2}$; reaction 4, $\mathrm{CH}_{4}+\mathrm{OH}=\mathrm{CH}_{3}+\mathrm{H}_{2} \mathrm{O}$; reaction $5, \mathrm{CH}_{3}+\mathrm{HO}_{2}=$ $\mathrm{CH}_{3} \mathrm{O}+\mathrm{OH}$; reaction $6, \mathrm{CH}_{2} \mathrm{O}+\mathrm{HO}_{2}=\mathrm{CHO}+\mathrm{H}_{2} \mathrm{O}_{2}$.

same set of significant reactions) while keeping unaltered the heterogeneous scheme. The origin of the differences between the Warnatz and GRI-3.0 schemes was investigated with the SA of Fig. 7b, c and with a radical reaction flux analysis. Over the entire preignition zone, the $\mathrm{OH}, \mathrm{H}$, and $\mathrm{O}$ radical concentrations in GRI-3.0 were about three times higher than in Warnatz's scheme. The $\mathrm{H} / \mathrm{O}$ reaction subset was not responsible for these differences as shown by interchanging the $\mathrm{H} / \mathrm{O}$ subsets of both schemes and computing anew. Moreover, this is consistent with our recent $\mathrm{H}_{2}$ /air CST comparative investigation of various hetero/homogeneous schemes [20]. The main fuel-depletion step was, in both schemes, $\mathrm{CH}_{4}+\mathrm{OH}=\mathrm{CH}_{3}+\mathrm{H}_{2} \mathrm{O}$; although the rate constant of this reaction was $30 \%-40 \%$ higher in GRI-3.0 over the temperature range 1000-1400 K (representative of the near-wall gas, see Fig. 3), this was not the main reason for the ignition differences of the two gaseous schemes. The $\mathrm{CH}_{3}$ consumption in GRI-3.0 proceeded fast through $\mathrm{CH}_{3}+\mathrm{HO}_{2}=$ $\mathrm{CH}_{3} \mathrm{O}+\mathrm{OH}$, which was the main production step for $\mathrm{OH}$, and subsequently via $\mathrm{CH}_{3} \mathrm{O}+\mathrm{M}=\mathrm{H}+$ $\mathrm{CH}_{2} \mathrm{O}+\mathrm{M}$, which was the main production step for $\mathrm{H}$; O was produced via the branching step $\mathrm{H}+$ $\mathrm{O}_{2}=\mathrm{OH}+\mathrm{O}$. In the scheme of Warnatz, however, the slower route $\mathrm{CH}_{3}+\mathrm{O}_{2}=\mathrm{CH}_{2} \mathrm{O}+\mathrm{O}+\mathrm{H}$ provided the main production mechanism for both $\mathrm{H}$ and $\mathrm{O}$, whereas $\mathrm{OH}$ was produced primarily via $\mathrm{H}_{2} \mathrm{O}_{2}+\mathrm{M}=2 \mathrm{OH}+\mathrm{M}$. Furthermore, of the significant C-containing reactions of Warnatz's scheme, reaction $4\left(\mathrm{CH}_{3}+\mathrm{O}_{2}=\mathrm{CH}_{2} \mathrm{O}+\mathrm{O}+\mathrm{H}\right)$ had the strongest pressure dependence: a factor-of-two increase in the pre-exponential constant of this reaction resulted in $x_{\text {ig }}$ agreement within $14 \%$ to the measurements and good prediction of the V-shaped flames at pressures $\geq 8$ bar, while still maintaining an $x_{\text {ig }}$ agreement within $6 \%$ at lower pressures. Therefore, reaction 4 is one possible source for the discrepancies of Warnatz's scheme at pressures $\geq 8$ bar. Finally, the differences between the Warnatz and GRI-3.0 schemes were verified with independent, gaseous studies: the SENKIN [21] package was used to evaluate ignition delay times of purely gaseous $\mathrm{CH}_{4}$ /air mixtures having $0.3 \leq \varphi \leq 0.4,1 \leq$ $p \leq 10$ bar and $1000 \leq T_{\text {IN }} \leq 1400 \mathrm{~K}$. GRI-3.0 yielded always ignition delay times three to five times shorter compared with those of Warnatz's scheme. The present experiments have thus shown that, under CST-relevant conditions, GRI-3.0 is inadequate.

\section{Conclusions}

The homogeneous ignition of fuel-lean $\mathrm{CH}_{4}$ /air mixtures over Pt was investigated at pressures up to 10 bar. Predictions with the hetero/homogeneous schemes of Deutschmann/Warnatz were in good agreement (within $\sim 10 \%$ ) with the measured homogeneous ignition distances $\left(x_{\mathrm{ig}}\right)$ and the established V-shaped flames at pressures $\leq 6$ bar, rendering the above schemes of particular interest to microturbine catalytic combustion applications; at pressures $\geq 8$ bar, however, a marked overprediction of $x_{\mathrm{ig}}$ was evident $(>25 \%)$ and in some cases the predictions did not reproduce the measured Vshaped flames. An increase in pressure inhibited the adsorption of $\mathrm{CH}_{4}$ due to the enhanced surface coverage by oxygen, but this effect was overtaken by the 
corresponding increase of the methane concentration. The scheme of GRI-3.0 underpredicted substantially the ignition distances (by 55\%-65\%) due to its significantly faster radical pool buildup in the induction zone.

\section{Acknowledgments}

Support was provided by the Swiss Federal Office of Energy (BFE), Office of Education and Technology (BBT), and Alstom Power of Switzerland.

\section{REFERENCES}

1. Deutschmann, O., and Schmidt, L. D., AIChE 44(11):2465 (1998).

2. Dogwiler, U., Benz, P., and Mantzaras, J., Combust. Flame 116:243 (1999)

3. Deutschmann, O., Maier, L. I., Riedel, U., Stroemman, A. H., and Dibble, R. W., Catal. Today 59:141 (2000).

4. Hickman, D. A., and Schmidt, L. D., AIChE 39(7):1164 (1993).

5. Dogwiler, U., Mantzaras, J., Benz, P., Kaeppeli, B., Bombach, R., and Arnold, A., Proc. Combust. Inst. 27:2275 (1998).

6. Mantzaras, J., and Benz, P., Combust. Flame 119:455 (1999).

7. Mantzaras, J., Appel, C., and Benz, P., Proc. Combust. Inst. 28:1349 (2000).
8. Glassman, I., Combustion, 3rd ed., Academic Press, London, 1996, p. 156

9. Kissel-Osterrieder, R., Behrendt, F., Warnatz, J., Metka, U., Volpp, H. R., and Wolfrum, J., Proc. Combust. Inst. 28:1341 (2000).

10. Warnatz, J., and Maas, U., Technische Verbrennung, Springer-Verlag, New York, 1993, p. 101.

11. GRI-3.0, Gas Research Institute, 1999, www.me. berkeley.edu/gri_mech.

12. Mantzaras, J., Appel, C., Benz, P., and Dogwiler, U., Catal. Today 59:3 (2000).

13. Kee, R. J., Rupley, F. M., and Miller, J. A., Sandia report SAND89-8009B, July 1996.

14. Coltrin, M. E., Kee, R. J., and Rupley, F. M., Sandia report SAND90-8003C, July 1996.

15. Kee, R. J., Rupley, F. M., and Miller, J. A., Sandia report SAND87-8215B, July 1996.

16. Warnatz, J., Allendorf, M. D., Kee, R. J., and Coltrin, M. E., Combust. Flame 96:393 (1994).

17. Kee, R. J., Dixon-Lewis, G., Warnatz, J., Coltrin, M. E., and Miller, J. A., Sandia report SAND86-8246, July 1996

18. Warnatz, J., Maas, U., and Dibble, R. W., Combustion, 2nd ed., Springer-Verlag, Berlin, 1999, p. 78.

19. Dalla Betta, R. A., and Rostrup-Nielsen, T., Catal. Today 47:369 (1999).

20. Appel, C., Mantzaras, J., Schaeren, R., Bombach, R., Inauen, A., Kaeppeli, B., Hemmerling, B., and Stampanoni, A., Combust. Flame 128:340 (2002).

21. Lutz, A. E., Kee, R. J., and Miller, J. A., Sandia report SAND87-8248, July 1996.

\section{COMMENTS}

A. M. Dean, Colorado School of Mines, USA. Your slide shows the reaction $\mathrm{CH}_{3}+\mathrm{O}_{2}=\mathrm{CH}_{2} \mathrm{O}+\mathrm{O}+\mathrm{H}$ as being very sensitive. I am surprised at this product state. I would have expected perhaps: $\mathrm{CH}_{3}+\mathrm{O}_{2}=\mathrm{CH}_{2} \mathrm{O}+\mathrm{OH}$ and $\mathrm{CH}_{3}+\mathrm{O}_{2}=\mathrm{CH}_{3} \mathrm{O}+\mathrm{O}$. Can you comment on your choice of products?

Author's Reply. The reaction with the relevant products is not our choice but is given in the original mechanism of Warnatz (Ref. [10] in paper) with specific reaction param-

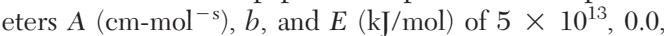
and 120 , respectively.

We have also tested the more recent $\mathrm{C}_{1}$ mechanism of Warnatz (Ref. [18] in paper) where the reaction $\mathrm{CH}_{3}+$ $\mathrm{O}_{2}=\mathrm{CH}_{2} \mathrm{O}+\mathrm{OH}$ is used instead. Although the 1999 mechanism is more detailed in number of species and reactions and it worked well at high pressures ( $>8$ bar), it performed poorly at low pressures: it underpredicted the homogeneous ignition distance by about $50 \%$ at atmospheric pressure. We opted to use the Warnatz mechanism as it had shown very good performance in our previous atmospheric pressure studies (Ref. [5] in paper). We will report in future publications the differences between these two mechanisms, as well as other additional gaseous mechanisms.

Michael Försth, Chalmers University of Technology, Sweden. Different surface reactions seem to affect the homogeneous ignition differently; some reactions promote ignition, while others inhibit ignition. So, finally, from a homogeneous ignition point of view, what is the total effect of the catalytic surface as compared to an inert surface? In addition, how was the cleanliness of the catalytic surface checked?

Author's Reply. We have to distinguish between purely chemical effects induced primarily by the heterogeneous radical adsorption/desorption reactions (and secondarily via the heterogeneous product formation) and the transport effects induced by the near-wall fuel depletion due to the catalyst, which acts as a sink for the fuel. The near-wall fuel depletion is, in all cases, the strongest inhibitor of homogeneous ignition since it deprives fuel from the nearwall hot ignitable mixture. This strong inhibition effect has 
been elaborated, for example, in our previous study (Ref. [5] in paper) with a comparative study between inert and catalytic cases.

The radical adsorption/desorption reactions have a net inhibiting effect on homogeneous ignition as discussed in the second paragraph of the Results and Discussion section: "In the early preignition zone, $\mathrm{OH}$ was produced by the surface and consumed by the gaseous pathway; however, at the latest preignition stages $(x>145 \mathrm{~mm})$ the heterogeneous pathway became a sink of $\mathrm{OH}$ radicals that resulted in an overall mild homogeneous ignition inhibition. This was confirmed by removing both $\mathrm{OH}$ adsorption/ desorption reactions and computing anew; the $x_{\mathrm{ig}}$ was reduced by about 10\%." This behavior has been found in our atmospheric-pressure methane/air study (Ref. [5] in paper) and the hydrogen/air study (Ref. [20] in paper).

The catalytic surfaces have been examined with XPS (Ref. [20] in paper) after the PVD Pt deposition and have assessed the presence of pure platinum on the surface (which is not surprising given very thick, $2.2 \mu \mathrm{m}$, Pt layer coating). During experimental runs, the catalytic activity is monitored in order to guarantee that it remains the same with that of the fresh sample.

Robert Kee, Colorado School of Mines, USA. Your observations on the gas-phase ignition are very interesting, especially from the scientific viewpoint. From the viewpoint of application, for example, in microturbines, is it desirable to have homogeneous combustion within the channel.

Author's Reply. The interest for homogeneous ignition studies in the catalytic combustion of gas turbines stems primarily from safety considerations. Gas-phase combustion can cause catalyst meltdown, and in this respect, the delineation of safe operating conditions that ensure no homogeneous ignition inside the catalytic channel is an important reactor design issue. This is precisely the objective of this work, that is, to provide validated heterogeneous/ homogeneous reaction schemes for design purposes.

There could be, however, cases where gas-phase combustion inside the catalytic reactor in indeed desirable. This has to be seen in conjunction with the degree of nonadiabaticity that the reactor is designed. In gas-turbine applications, for example, alternate channel coating provides a high degree of non-adiabaticity and certainly, in these cases, gas-phase combustion is undesirable, as it would lead to channel temperatures well above their design values. In cases with no substantial degree of non-adiabaticity, however, the gaseous and catalytic combustion temperatures can be roughly the same and gas-phase combustion can be tolerated. 